\title{
Investigation of the prestressed beams and glass-window panels at a shopping centre
}

\author{
Andreea-Terezia Mircea ${ }^{1, *}$ \\ ${ }^{1}$ Technical University of Cluj-Napoca, Department of Civil Engineering and Management, 400114 Cluj-Napoca, Romania
}

\begin{abstract}
In today's rapidly changing demands of commercial buildings, designers, manufacturers, contractors, and installers face the necessity to advance their methods, to improve techniques, and generally to stay competitive under all constraints of time, budget, codes and client desires. Building with precast concrete elements provides quick and cost-efficient production, along with flexible, independent interior design. The show-window of the investigated commercial building is divided into several glass panels. Having only upper and lower grip, the glass window panels with very tall heights, are subject to deformation. In order to resist, panels are provided with U-shaped profiles or/ and perimeter rails. The critical points are the glass panels' support, so the ceiling and floor fastenings have to be very solid, as well as qualitatively superior designed and executed. This paper aims to highlight some relevant aspects regarding the investigation of the metal fixing system designed to connect show-window panels to prestressed concrete ceiling beams at a commercial building.
\end{abstract}

\section{Introduction}

In recent years, the construction sector, as one of the most dynamic and flexible economy sectors, faces rapidly changing demands. Especially for commercial buildings like shopping centres (Figure 1), the designers, manufacturers, contractors, and plumbers go along with the necessity to advance and integrate their methods, to improve techniques, and generally to stay competitive under all constraints of time, budget, codes and client desires.

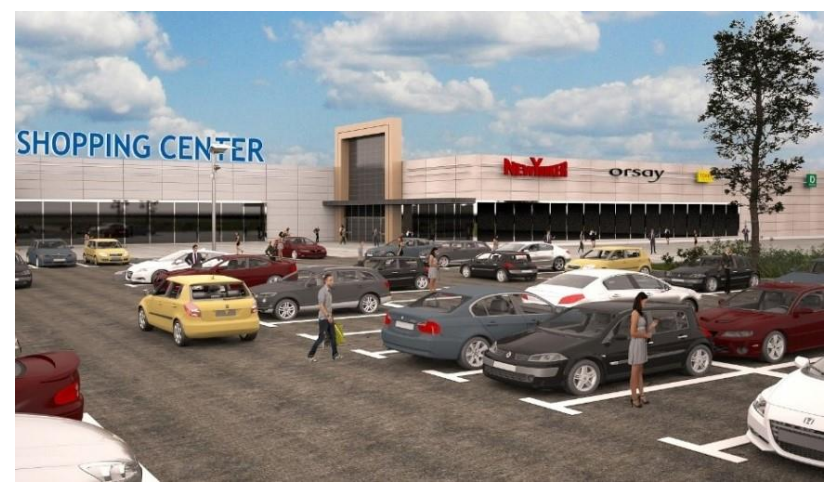

Fig. 1. The investigated commercial building.

In this regard the main advantage of building with precast concrete elements is a considerable shortening of construction time without climatic influences. This building method provides quick and cost-efficient production, along with flexible, independent interior design, also with significant advantages concerning fire prevention, sound protection and thermal insulation.
The show-window of the investigated commercial building is divided into several glass panels. Having only upper and lower grip, the glass window panels with very tall heights, are subject to deformation. In order to resist, fixed panels are positioned with U-shaped profiles or/and perimeter rails. The critical points are the glass panels' support, so the ceiling and floor fastenings have to be very solid, as well as qualitatively superior designed and executed.

\section{Detailing Analysis}

Fastening systems are used to create non-permanent connections that can be removed or dismantled without damaging the joining components.

The investigated fastening system placed between the show-window panels and the ceiling beams consists of U-shaped metallic profiles mounted to the prestressed concrete beams through on-site drilled channels onto the bottom flange. These were made by penetrating the concrete core between the reinforcement bars, without damaging them. The perforated channels have a slightly larger diameter than the screws that were inserted by hammering. The weakening of a section through channels and perforations drilled between reinforcement (active or passive bars) results in generating loose zones where stress concentrations get at higher levels (in this case above the level of service) and have, as a result, cracks directed to these areas.

However, the problem that can arise in the analyzed situation is the redistribution [1] of the bending moments along the ceiling beams (i.e. secondary beams), due to the change of the static scheme over time, due to the

* Corresponding author: andreea.mircea@ ccm.utcluj.ro 
change of the static scheme over time consequent to the beams' gravitational time-dependent movement.

The fixing method of the fastening system is presented in Figure 2.
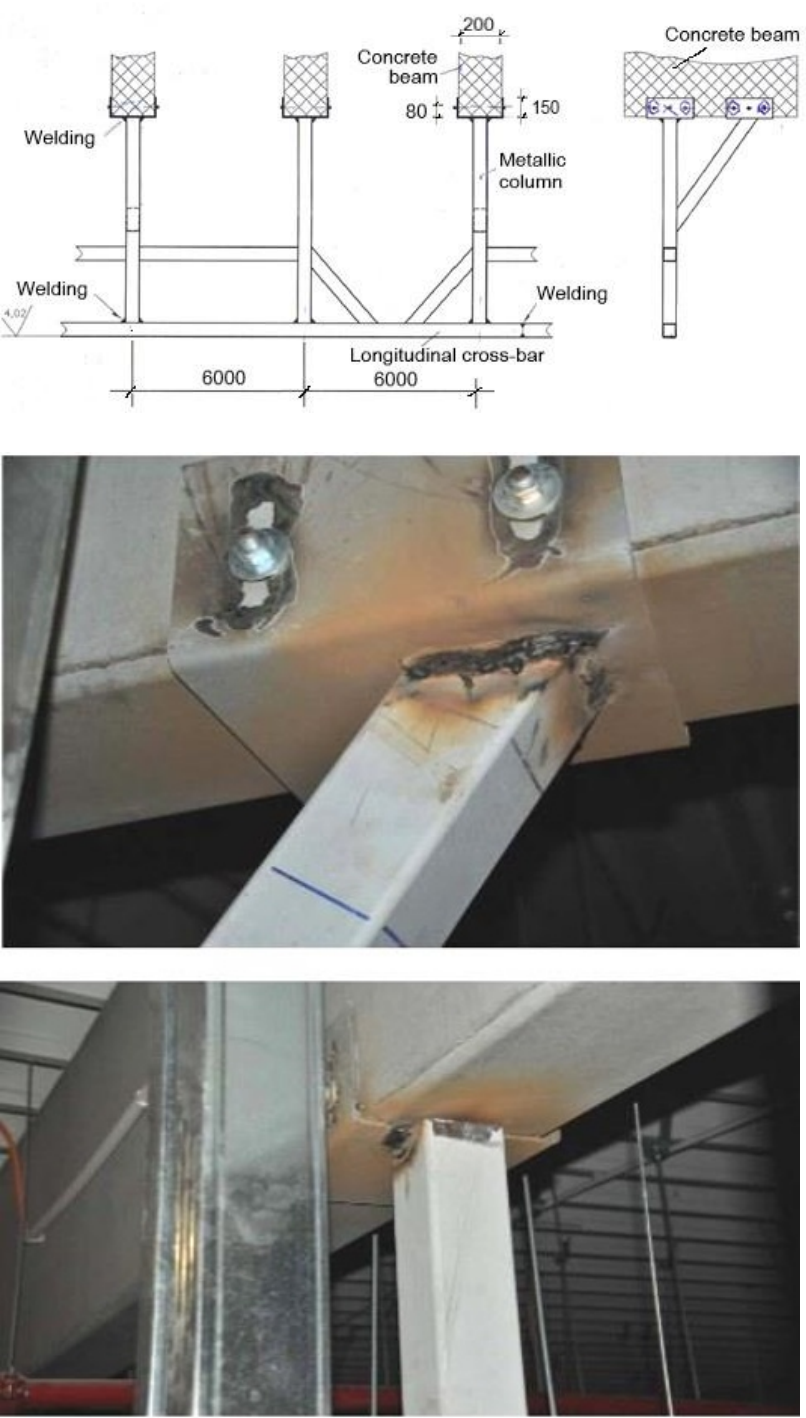

Fig. 2. Fixing method of the fastening system on the beams.

The rail for elastic fastening of the glass panels is shown in Figure 3.

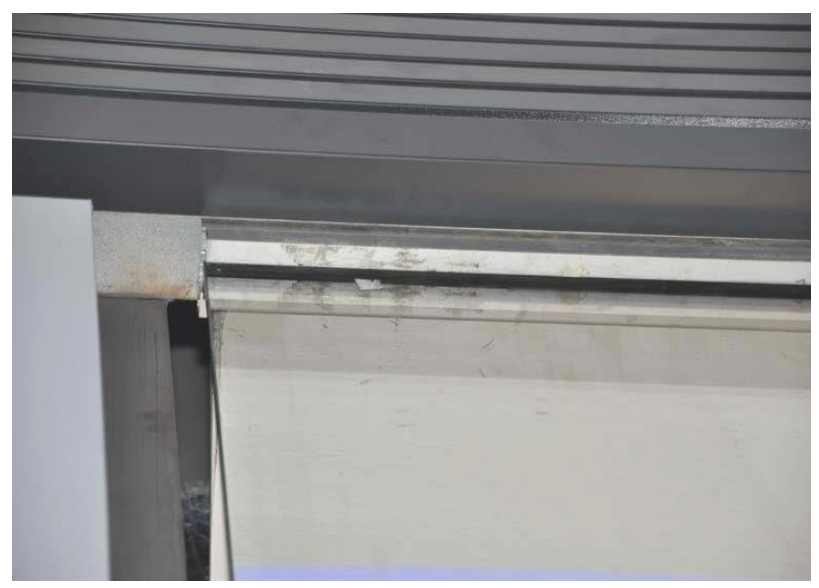

Fig. 3. The rail for elastic fastening of the glass panels
Analyzing the overlapping layout of the glass window panels with the structure, it can be considered that the ceiling beam, as a simply supported beam, has to resist, beside its self-weight, also the following loads, presented in Table 1:

Table 1. Loads at the roof level.

\begin{tabular}{|l|c|c|c|}
\hline \multicolumn{1}{|c|}{ Load } & $\begin{array}{c}\text { Type of } \\
\text { load }\end{array}$ & $\begin{array}{c}\text { Characteristic } \\
{\left[\mathrm{kN} / \mathrm{m}^{2}\right]}\end{array}$ & $\begin{array}{c}\text { Long term } \\
{\left[\mathrm{kN} / \mathrm{m}^{2}\right]}\end{array}$ \\
\hline $\begin{array}{l}\text { 1. Self weight } \\
\text { plated sheet }\end{array}$ & Permanent & 0.20 & 0.20 \\
\hline 2. Mineral wool & Permanent & 0.25 & 0.25 \\
\hline 3. PVC membrane & Permanent & 0.05 & 0.05 \\
\hline 4. Equipment & Permanent & 0.25 & 0.25 \\
\hline 5. False ceiling & Permanent & 0.25 & 0.25 \\
\hline 6. Snow & Variable & 1.60 & 0.64 \\
\hline
\end{tabular}

\section{Results and Discussion}

Structural analysis of the secondary prestressed concrete beams reveals the time dependency of the deflections as shown in the diagrams presented in Figures 4-6.

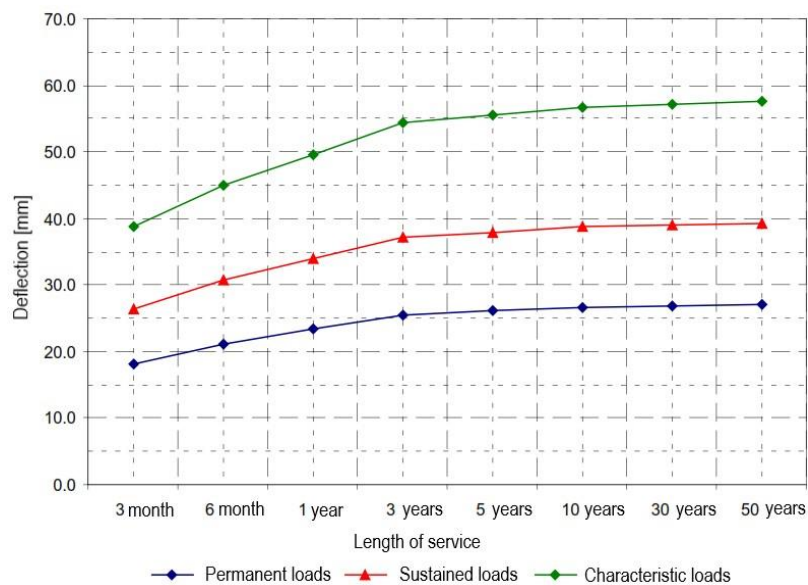

Fig. 4. Deflection variation of the simply supported secondary beam with service time.

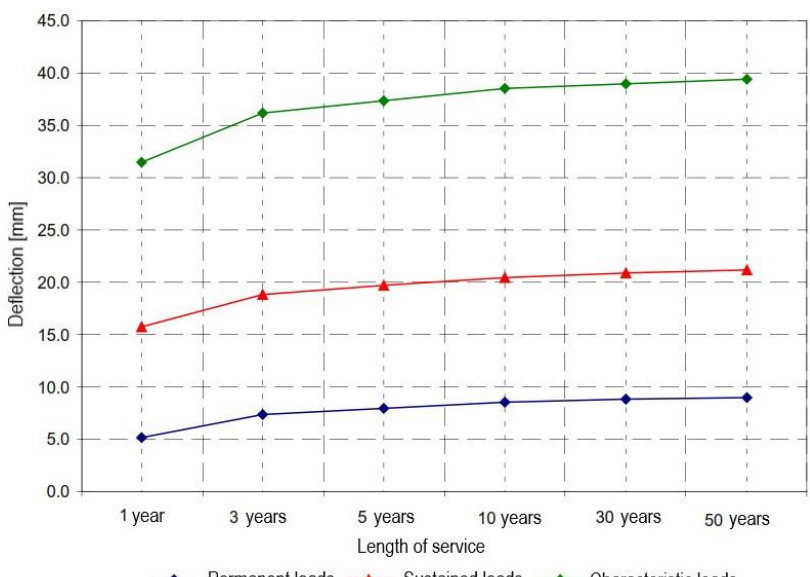

Fig. 5. Deflection increase under service conditions within 3 month, with load level corresponding to permanent loads. 


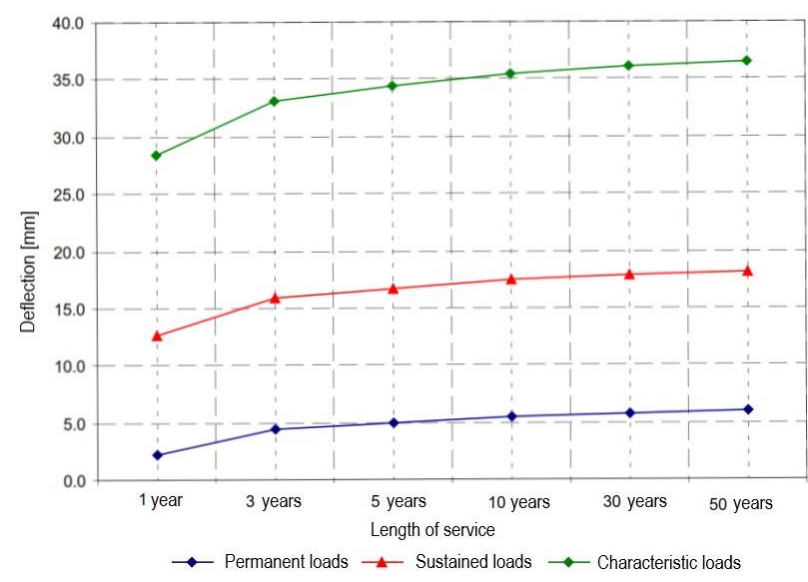

Fig. 6. Deflection increase under service conditions within 6 month, with load level corresponding to permanent loads.

The deformation of a structure under sustained load, can cause it to change shape. Creep does not necessarily cause concrete to fail or break apart; the deformation increases at a decreasing rate during the period of loading [2]. Thus, it is observed that deflection increased to $15.7 \mathrm{~mm}$ at 3 months and to $12.7 \mathrm{~mm}$ at 6 months. Approximately, 25-30\% of the total creep takes place in the first month under sustained loading, and about 50-75 $\%$ of the total creep occurs during the first half year of sustained loading in concrete sections of moderate size [3]. Consequently, it can be presumed that at about 1 year, the static scheme will be changed, middle intermediary supports will occur.

A vertical movement of the glass panel's rail support up to a maximum of $10 \mathrm{~mm}$ was estimated. In order to determine its safety and suitability, as well as to find out if the glass panel has enough stiffness to ensure effort redistribution, a second order Finite Element Analysis was performed using the RISA 3D Program.

Glass has a standard Young's modulus of 70 GPA, and a compressive strength of $100 \mathrm{MPa}$, in accordance with the technical files of the manufacturer. For a thickness of $10 \mathrm{~mm}$ and $20 \mathrm{~mm}$, Figure 7 reveals that a show-window panel has a high stiffness, and can be considered as a rigid support.

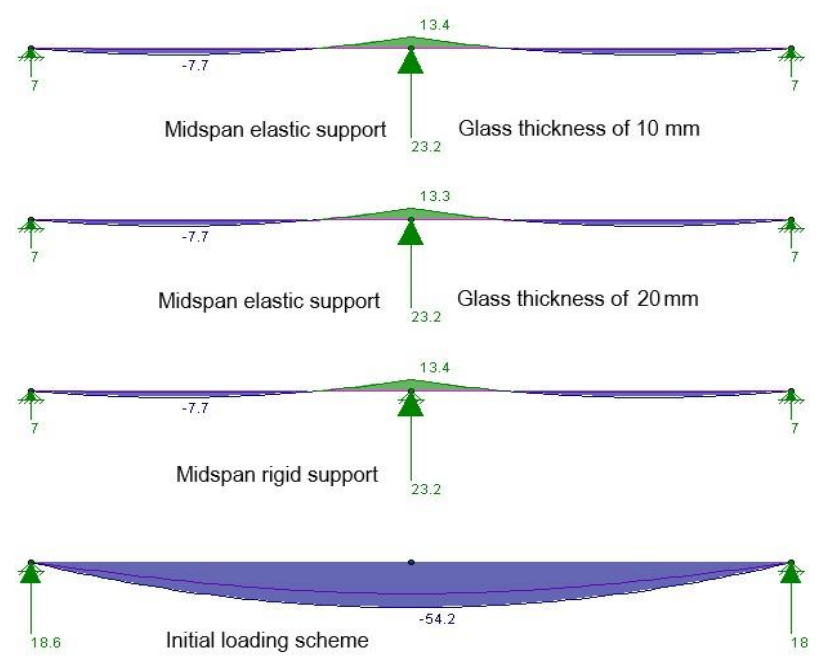

Fig. 7. Redistribution of bending moments under sustained loads.
Stress redistribution takes place because statically indeterminacy generates secondary bending moments due to prestressing. This modifies the time behaviour of the secondary beam, as the time dependent deformations increase, the cracking pattern will change and the safety level will decrease.

Related to the fastening system placed between the show-window panels and the ceiling beams, another aspect is that in most of the joints, and even in the areas of contact with the prestressed concrete elements (see Figure 2), the anticorrosive film was destroyed by welding. These areas are vulnerable to accelerated corrosion, and the contact of corroded elements with the surface of the concrete will lead to electro-chemical corrosion of steel rebar reinforcement, thus reducing the durability of the concrete prestressed elements.

As presented in Figures 8, 9 and 10, the redistribution of the bending moments will take place in every scenario. The stress concentrations under the contact zone may reach $17 \mathrm{MPa}$, much below the compressive strength value of $100 \mathrm{MPa}$, without local buckling. Also the generally buckling of the secondary beam is excluded, even for a deflection of $10 \mathrm{~mm}$ (Span/400).

Any future agglomeration of snow that leads to overtaking the level of long-lasting loads is likely to accelerate the phenomenon, and might lead to an earlier failure of the secondary beams.

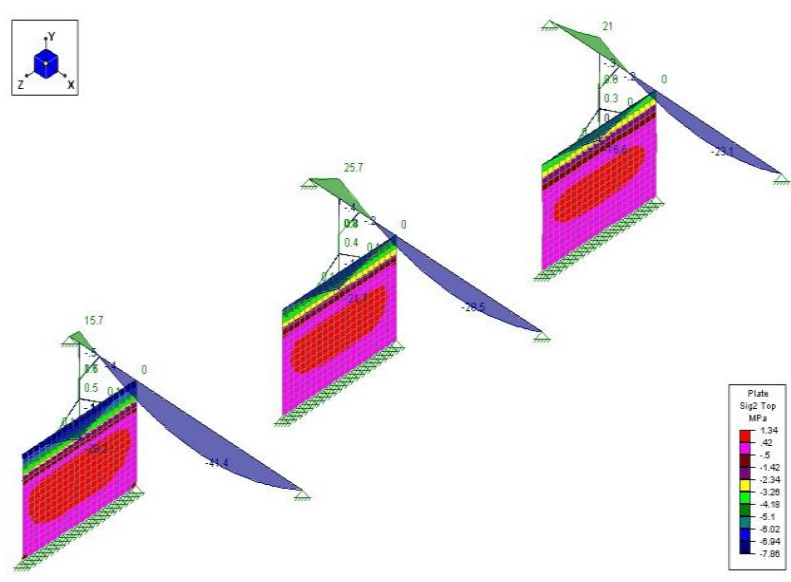

Fig. 8. Long term snow loads

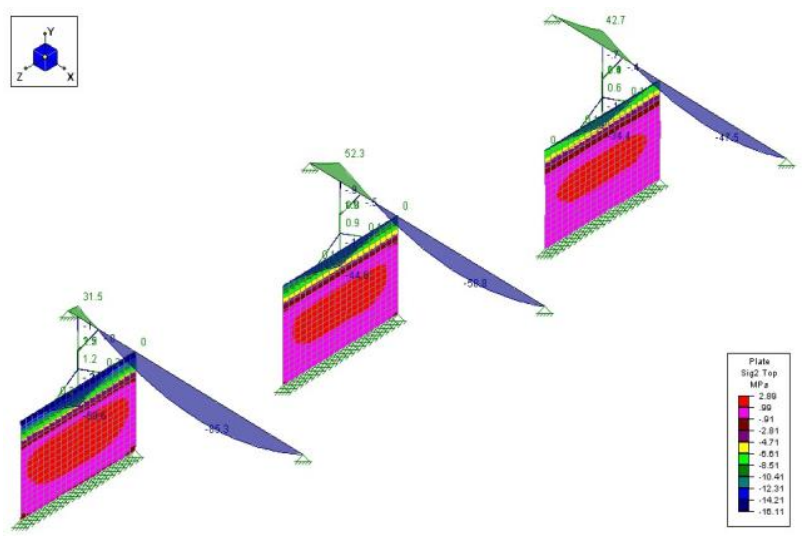

Fig. 9. Total sustained loads 


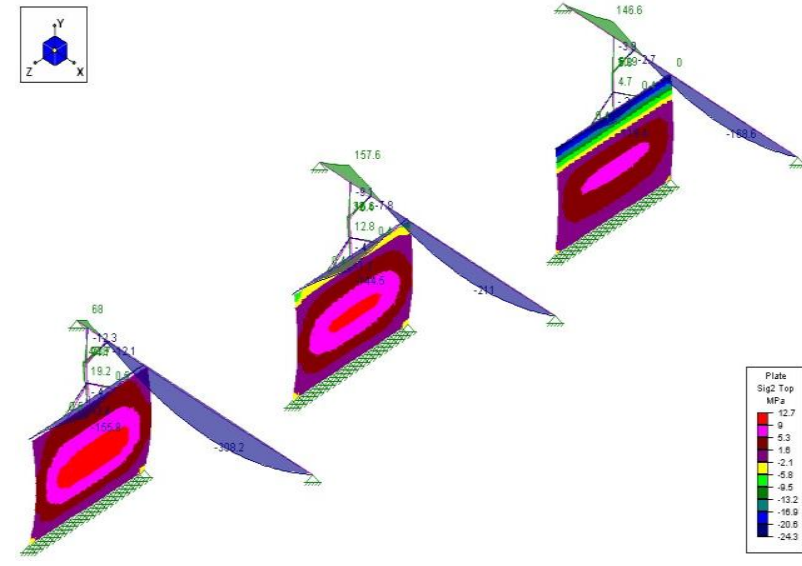

Fig. 10. Efforts at ultimate limit states.

\section{Conclusions and Recommendations}

The full life-cycle approach of any construction has to be considered with all its interdependencies, and from the most early design phases [4]. Identifying opportunities, precise formulation, setting goals, priorities, and systematic seek for pragmatic results [5] have to be part of the building companies' management objectives for any construction project. Innovative methods have to be applied, so as structural performance to be improved, and the architectural characteristics to be preserved [6].

The conclusions of this study can be drawn for all prestressed concrete beams from the investigated commercial building having this type of fastening system, placed between the show-window panels and the ceiling beams (secondary beams) bottom flange. So, the investigations carried out lead to the following conclusions:

- Given the fact that drilling of channels through the prestressed concrete beam didn't damage the reinforcement bars, the safety level of the element remains virtually unaffected;

- The drilling of channels through dense reinforced areas of prestressed concrete beams is a risk that may not be covered by documents made on site (e.g. possible loss of steel area, vulnerability to corrosion);

- The fixing method of the show-windows is defective because it doesn't ensure the time dependent control of the long time deformation and secondary (parasite) stresses can occur in the prestress beams consequently to the interaction with the show-window panels (i.e. changing of the statically scheme).

To avoid these situations it is recommended:

- To restore the anticorrosive film protection of the fastening system placed between the glass window panels and the ceiling beams;

- To monitor the fastening system behaviour;

- If monitoring results state the compensation of the displacement tolerance, the structural designer shall be immediately consulted, in order to implement the necessary measures (e.g. fastening the show-windows by areas of minimum bending stresses - in the middle of the beams' height with adequate time dependent tolerances).

\section{References}

1. T.Y. Lin, N.H. Burns, Design of Prestressed Concrete Structures, ISBN 10: 0471018988 / ISBN 13: 9780471018988, Published by Wiley (1981)

2. A.K. Gambali, N.K. Shanagam, Creep of Concrete, IJEDR | 2, Issue 4 | ISSN: 2321-9939 (2014)

3. EN 1992-1-1:2004 Eurocod 2: Design of concrete structures - Part 1-1: General rules and rules for buildings (2004)

4. A.T. Mircea, Selecting Environmentally Compatible Materials for Priority Integration into the Design Process, 17th International Multidisciplinary Scientific GeoConference SGEM 2017, Vol. 17-62, Section Green Buildings, Technologies and Materials, Albena, Bulgaria, pp. 409-416. (2017) doi: 10.5593/sgem2017/62/S26.052

5. S.A. Ciplea, Costs Reduction in Civil Engineering Through Optimization Methods, The 2nd Review of Management and Economic Engineering Management Conference (RMEE), Management of Crisis or Crisis of Management, Cluj-Napoca, Romania, pp. 71-76. (2011)

6. D. Sucala, I.N. Sucala, S.A. Ciplea, Technologically Consolidation Fundations Using Insulation Method Based on the Construction, 17th International Multidisciplinary Scientific GeoConference SGEM 2017, Vol.17-14, Applied and Environmental Geophysics, Albena, Bulgaria, pp. 437-444. (2017) doi: 10.5593/sgem2017/14/S05.055 